\title{
Heavenly insemination
}

\author{
Hugh Montefiore
}

I SUPPOSE that it is no more strange that an outstanding biologist such as Francis Crick should give his views on cosmology than that a distinguished astronomer such as Fred Hoyle should pronounce on molecular biology. To an outsider, these are both welcome pointers towards an integration of the sciences. So perhaps it was not outrageously odd to give Crick's book to a theologian for review; but he must walk warily on alien territory.

Crick writes ostensibly to answer Enrico Fermi's famous question, "If there are intelligent beings in the galaxy, why aren't they here?', and he assesses the hypothesis known as Directed Panspermia, that is to say, a variant of Arrhenius's nineteenth-century theory, modified in that Crick considers whether life was deliberately planted on Earth. His book has nothing in common with Hoyle's views propounded in Evolution from Space (Dent, 1981). Crick, for example, does not seriously question whether the period needed for life to emerge by natural process requires a time span longer than the age of the Earth. Nonetheless he seems somewhat sensitive to his wife's criticism that his work may seem more like science fiction than a Nobel Prize winner's critique of a scientific theory. Perhaps for this reason Crick takes the opportunity (as his title suggests) to give his view on life itself, its origin and nature. Written with enviable simplicity and free of abstruse technicalities, it is as a result devoid of any annotation.

The answer that Crick gives to Enrico Fermi is that life on Earth could well have originated elsewhere in the Galaxy, and that there has been time enough for intelligent beings to evolve elsewhere in a suitable environment and to have despatched prokaryotic and eukaryotic microorganisms by rocket to this planet, whence life here may have developed. Crick, however, admits that this theory of Directed Panspermia, although plausible, suffers from extreme paucity of evidence. He calls it "premature". Crick the human being affirms: "Once the scale and nature of the galaxy is appreciated, it is intolerable not to know whether we are its sole inhabitants"; but Crick the scientist is cautious: "I cannot myself see just how we shall ever

Life Itself: Its Origin and Nature. By Francis Crick. Pp.192. UK ISBN 0-356-07736-5; US ISBN 0-671-25562-2. (Macdonald/Simon and Schuster: 1982.) $£ 7.95, \$ 13.95$.

decide how life originated".

A small measure of support for Directed Panspermia is seen in the almost uniform nature of the genetic code. Some factors, however, Crick does not consider; for example, the origin of some bacteria with properties which seem unlikely to have

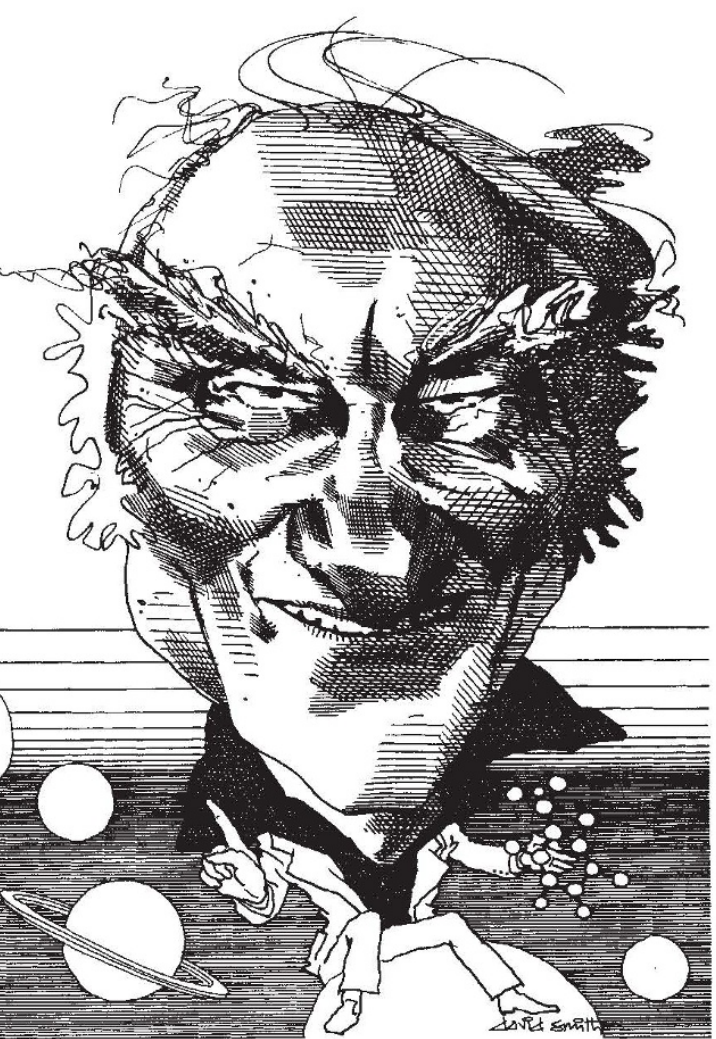

evolved to meet our earthly conditions. And it is surprising that he does not mention the microfossils which suggest that eukaryotes existed at least as early as prokaryotes, although the initial gap of a billion years means that we do not know how either evolved. As for the supposedly random emergence of life in the prebiotic broth, Crick writes:

It is impossible for us to decide whether the origin of life here was a very rare event or one almost certain to have occurred;

yet elsewhere he writes of it as "an infinitely rare event" and even admits that

an honest man, armed with the knowledge available to us now, could only state that, in some sense, the origin of life appears at the moment to be almost a miracle.

I wonder, however, whether Crick's view will continue to prevail that "it seems almost impossible to give any numerical value to the probability of what seems a rather unlikely sequence of events" leading to the emergence of life. In any case the really fundamental problems remain to be solved; how DNA, RNA and enzymes were originally formed, and how the first cell, with its reproductive mechanism, came into existence.

Whether all the dense and sober argumentation of Crick can be validated, I am not in a position to judge. Such matters as available environments for life to emerge elsewhere, the length of time involved, the mode of travel and the duration of the voyage cannot be more than scientific speculation. Crick's scientific writing is lucid, magisterial and suitably cautious ("seems to be", "apparently", "so far as we know"). But in Chapter 15 ("Why Should We Care?") the tone abruptly alters. Crick the Nobel Prize winner has given way to Crick the human being. He reminds me here of those days in Cambridge when he offered a cash prize for the best secular use of a college chapel. When it comes to religious beliefs, gone are the qualifications and dogmatic certainty takes over. "Most modern scientists do not subscribe to any of them" (has he carried out a scientific survey?); and

The plain fact is that the myths of yesterday which our forebears regarded not as myths but as the living truth, have collapsed, and while we are uncertain whether we can successfully use any of the remaining fragments, they are too rickety to stand as an organized interlocking body of beliefs [italics mine].

Francis Crick's personal convictions will doubtless be read with respect; but he would put us in his debt if he would give some explanation of their logical connection with the natural sciences of which he is such a pre-eminent practitioner. Wherein, for example, lies a scientist's "almost boundless optimism concerning his ability to forge a new set of beliefs"? It might seem to some, that the dreadful threat of thermonuclear war overhanging 
the civilized world, with one-fifth of all scientists at work on defence contracts, should fill us with almost boundless pessimism. Granted, however, "the tremendous success of science, especially in the last hundred years", what is the logical connection between scientific explanation and ultimate meaning, or between scientific knowledge and ultimate belief? Or again, what is the scientific basis for the phrase "outmoded religious beliefs"? For example, is a scientific evaluation of the origin of life compatible with a theistic concept of creation? Readers may wish that Crick had here argued his case rather than merely stated his conclusion. Seen from our anthropic viewpoint, a remarkable series of "coincidences" must have taken place onwards from the initial explosion which brought the cosmos into being, so as to make possible the eventual emergence of Homo sapiens (whether or not ours is the only form of intelligent life in the Universe). These "coincidences" certainly occurred. They may be due to complex sequences of random and meaningless events. But they are also compatible with divine providence. Crick tells us that in considering the origin of life a "gut reaction" is likely to be superficial or misleading. Not all intuitions however deserve to be described in such pejorative terms. Spiritual insights are not to be despised as adequate explanations to such questions which, despite Dr Crick's almost boundless optimism, seem to transcend the fields of scientific investigation.

Hugh Montefiore is Bishop of Birmingham. quite similar new and gentler world-views, that do away with the body-mind dichotomy and the idea of the control of nature in favour of an ecological perspective in which the distinctions between subject and object, value and fact are deliberately blurred. Both authors are deeply impressed by what they see as a convergence with Eastern philosophy (YinYang, Zen Buddhism) of the ideas in quantum physics; both condemn the excesses of reductionism in favour of holism; both write for the general reader (otherwise I would not dare to review them) but in a scholarly fashion, with detailed notes and references; both regard Gregory Bateson's Mind and Nature (Dutton, 1979) as the most seminal modern work; both have the same critically respectful attitude to Freud, while preferring the development of his ideas by Carl Jung, Wilhelm Reich, Ronald Laing and Herbert Marcuse. Finally, both are centrally concerned with describing the misery of the modern world with its violence, poverty, consumerism, alienation, inflation, drug dependence, lunatic arms race and ecological destructiveness. In this last respect they are, of course, not alone. In contrast to the Meadows' Limits of Growth (Universe Books, 1972), with which they have otherwise much in common, they are cautiously optimistic because they see the new scientific world-view already emerging in North American culture.

Differences between these two books are largely matters of emphasis. Capra, a physicist, is particularly good in describing the development of physics from Newton to the present and is careful to point out which of the modern theories he adheres to are still controversial, for example, Chew's S-matrix theory. While he represents it in a language understandable to the layman and admits that he singled it out because it supports his broader views, it remains impossible for the non-physicist to understand its significance. Berman, a historian of science, writes most interestingly about Newton's psychological conflicts and complexities, and goes altogether more into psychological and political matters. While he, as much as Capra, admires Bateson whose thoughts and sources he describes in greater detail with particular emphasis on the principle of the essential incompleteness of knowledge, he also recognizes that some of Bateson's concepts are double-edged and could be exploited for totalitarian and anti-intellectual purposes; of which he strongly disapproves.

Two major common themes in these books deserve, however, critical comment. The first is the postulated link between the current malaise in the industrialized world and the mechanistic assumptions of Newtonian science; the second and related theme is the reductionism-holism issue.

A yearning to make coherent sense out of one's experience of being alive is probably universal; in Capra and Berman, 